\title{
Saúde e ambiente como pautas de interesse do Movimento de Mulheres Camponesas
}

\section{Health and environment as guidelines of interest of the Peasant Women's Movement}

\author{
Andressa Bertoncello Valandro* \\ Rosana Maria Badalotti** \\ Maria Elisabeth Kleba ${ }^{* * *}$
}

Palavras-chave:

Saúde

Ambiente

Mulheres Camponesas

Keywords:

Health

Environment

Peasant Woman
Resumo: O Movimento de Mulheres Camponesas (MMC) é uma organização de mulheres residentes/trabalhadoras do campo que emerge em diferentes regiões do Brasil durante a década de 1980. Caracteriza-se por ser um movimento autônomo, feminista, classista e popular. Desde sua emergência tem acumulado importantes conquistas no que se refere à garantia de direitos para as mulheres do campo. Protagonista de uma forma peculiar de compreensão e intervenção sobre a realidade cotidiana, o MMC vem, ao longo de sua história, tecendo novas relações em diferentes dimensões da experiência humana. Deste modo, o artigo que ora se apresenta objetivou compreender as articulações entre os temas 'saúde' e 'ambiente', estabelecidas como pautas de interesse no interior do MMC. Trata-se de um estudo de abordagem qualitativa, com análise de documentos produzidos pelo próprio movimento e de pesquisa de campo (observação, entrevista e grupo focal) realizada entre 2015 e 2016 com mulheres integrantes do MMC/SC. Considera-se, a partir do estudo, que o MMC defende um projeto de agricultura camponesa, agroecológica e feminista, que exige repensar as relações entre os seres humanos e destes com o ambiente, compreendendo que suas escolhas e atitudes implicam diretamente na saúde humana.

Abstract: The Peasant Women's Movement (MMC) is a women's organization who live and work in the countryside and emerged in different regions of Brazil during the 1980s. It is characterized by being an autonomous, feminist, classist and popular movement. In the beginning it has accumulated important achievements in guaranteeing the rights of women in the countryside. Protagonist of a peculiar way of comprehension and intervention about daily life reality, the MMC come, throughout its history, weaving new relationships in different dimensions of human experiences. This way, the present article aimed comprehend the joints between 'health' and "environment" topics as guidelines of interest established within the MMC. It is a qualitative study, with analysis of documents produced by the movement itself and field research (observation, interview and focal group) performed between 2015 and 2016 with women members of the MMC/SC. It is considered, from the study, in which MMC fights for a project for peasant, agro-ecological and feminist agriculture that demands rethinking the relationships between human beings and theirs with the environment, understanding that their choices and attitudes impliclate directly on humans' health.

Recebido em 30 de outubro de 2017. Aprovado em 16 de fevereiro de 2018.

\footnotetext{
* Psicóloga, especialista em Psicologia Social, especialista em Saúde Coletiva, Mestre em Políticas Sociais e Dinâmicas Regionais. Atualmente cursando disciplina isolada no Programa de Pós-Graduação Mestrado/Doutorado em Psicologia, pela Universidade Federal de Santa Catarina UFSC. E-mail: <dessa@unochapeco.edu.br>.

** Doutorado Interdisciplinar em Ciências Humanas pela Universidade Federal de Santa Catarina (UFSC), docente do Programa de Pós-Graduação Stricto Sensu em Políticas Sociais e Dinâmicas Regionais - Unochapecó. E-mail: <rosana@unochapeco.edu.br>.

*** Doutorado em Filosofia pela Universität Bremen, UNI BREMEM, Alemanha. Docente do Programa de Pós-Graduação Stricto Sensu em Políticas Sociais e Dinâmicas Regionais - Unochapecó. E-mail: <lkleba@unochapeco.edu.br>
} 


\section{Introdução}

Os anos de 1970 e 1980 são emblemáticos no que diz respeito à organização da sociedade civil brasileira, culminando na emergência de diversos movimentos sociais com demandas que extrapolaram a busca por bens e serviços necessários para a sobrevivência, elevando as reivindicações ao patamar dos direitos sociais de igualdade, liberdade e democratização das relações sociais (GOSS; PRUDÊNCIO, 2004; GOHN, 2006; SCHERERWARREN, 2006).

Juntamente com a efervescência de organizações populares da época, os movimentos sociais do campo figuram, no cenário nacional, com ações paralelas em diferentes regiões brasileiras, destacando-se os três estados do Sul. Na Região Oeste catarinense, muitos destes movimentos ganham corpo, iniciando suas manifestações em momentos quase simultâneos, num espaço muito curto de tempo. A Igreja Católica - por intermédio da Teologia da Libertação, das Comunidades Eclesiais de Base e das Comissões Pastoral da Terra -, desempenhou papel importante na organização destes atores sociais coletivos. Eclodem as reivindicações nos mais diferentes âmbitos, dando início à trajetória do Movimento de Oposição Sindical, o Movimento dos Atingidos por Barragens (MAB), o Movimento dos Trabalhadores Rurais Sem Terra (MST) e o Movimento das Mulheres Agricultoras (MMA) - atualmente reconhecido como MMC, cuja atuação na área da saúde foi objeto deste estudo (POLI, 2008; BONI, 2012).

Visando uma participação interna mais igualitária e democrática e com base em uma lógica de contestação da realidade excludente gerada pela ideia de modernização da agricultura imposta aos camponeses entre os anos de 1970 e 1980, estes atores sociais passam a romper com os próprios limites no que diz respeito à sua participação política, trabalhando tanto internamente quanto externamente para se fortalecer enquanto coletivo e tornar visíveis suas causas e objetivos (MELUCCI, 2001; GOHN, 2006; SCHERER-WARREN, 2006; POLI, 2008).

Para as mulheres camponesas, o modelo de agricultura apresentado no pacote que orientava sua modernização, além de agravar a crise econômica entre as famílias do campo, acentuou expressivamente a cultura patriarcal já existente nas relações familiares, impondo uma condição de maior opressão e invisibilidade às mulheres. Este cenário impulsionou a criação de movimentos autônomos de mulheres do campo objetivando transformar esta realidade (BONI, 2012; CINELLI, 2013).

A especificidade dos temas "saúde e ambiente", mesmo que sempre tenham sido temas defendidos como pautas de interesse dos movimentos sociais, têm ganhado destaque nos últimos anos. Em breve pesquisa online para levantamento de dados sobre os temas, percebese que há um aumento nos registros documentais provenientes de estudos, pesquisas ou experiências práticas a partir de 2011. Estes foram impulsionados principalmente pela atuação dos movimentos na construção de uma política pública específica de promoção da equidade em saúde, com foco nas populações do campo, das florestas e das águas. A construção da referida política iniciou em 2004 e foi sancionada no ano de 2011, durante a XIV Conferência Nacional de Saúde.

Deste modo, o artigo que ora se apresenta, objetivou compreender as articulações entre os temas 'saúde' e 'ambiente' estabelecidas no interior do MMC. Trata-se de um recorte de pesquisa de mestrado realizada entre março de 2015 e dezembro de 2016, com abordagem qualitativa, trazendo para a discussão a análise de documentos produzidos pelo próprio $\mathrm{MMC}^{1}$, além de inserções analíticas produzidas a partir da pesquisa de campo (observação, entrevista exploratória e grupo focal). Para a técnica de observação utilizou-se o diário de campo como instrumento de registro de dados e informações ${ }^{2}$. Nas técnicas de entrevista e grupo focal, o número total de sujeitos participantes foram sete vinculados a seis regionais do $\mathrm{MMC} / \mathrm{SC}$, com destaque para a região Oeste de Santa Catarina ${ }^{3}$.

$\mathrm{O}$ artigo foi estruturado em dois itens, buscando atender ao objetivo proposto: o primeiro subtítulo contextualiza a trajetória do MMC, levando em consideração que no decorrer de seus 34 anos de história, muitos elementos do projeto 
de agricultura camponesa e agroecológica foram (e continuam) sendo construídos no cotidiano das mulheres e famílias camponesas, já realizando menções e análises sobre saúde e ambiente no interior do movimento. No segundo subtítulo, a ênfase é no projeto de agricultura camponesa e agroecológica, visando elucidar em que medida este projeto reflete as articulações entre saúde e ambiente para o movimento.

\section{Movimento de mulheres camponesas}

Quando a Comissão Pastoral da Terra inicia seu trabalho de educação popular com os agricultores e agricultoras, com base na Teologia da Libertação, a participação das mulheres cresce e começa a ser valorizada na região, o que fez com que esse público visualizasse as contradições existentes nos espaços que contavam com participação de homens e mulheres, nos quais os homens, na maior parte das vezes, assumiam lugares de poder socialmente reconhecidos e valorizados, perpetuando as relações de opressão e submissão da mulher (POLI, 2008). Esta constatação, juntamente com a reflexão sobre a submissão, opressão e sentimento de inferioridade expressa pelas mulheres, evidenciou uma necessidade concreta, que era organizar um movimento autônomo, cujo principal objetivo fosse a libertação de todas as mulheres (seja do campo ou da cidade) de qualquer forma de opressão (CINELLI, 2013).

Neste contexto, a partir da análise dos documentos públicos fornecidos pelo MMC, que resgatam a história de luta das mulheres, alguns aspectos da construção de uma identidade coletiva podem ser observados e analisados à luz da teoria da ação coletiva de Melucci (2001): a percepção da condição de opressão e subordinação por parte das mulheres, bem como a situação de invisibilidade gerada pela cultura patriarcal - a qual serve de referência para embasar a postura contrária do movimento - permite conceber a união das mulheres em torno de um "nós". Um "nós" que compartilha vivências e experiências comuns de desvalorização na condição de ser mulher e deseja, a partir desta união de forças, produzir mudanças na realidade cotidiana.
A partir da participação em diferentes atividades do MMC foi comum observar que as mulheres apresentam em seus discursos, manifestações que representam esta identificação com o grupo, como por exemplo: "Antes de participar do MMC eu achava que era normal o homem mandar e a mulher obedecer" ou "Foi assim com minha avó e com minha mãe, então eu achava que deveria ser assim comigo também". As falas, proferidas por diferentes mulheres e em ocasiões diversas (eventos, reuniões, grupo focal e entrevista), possibilitam observar um núcleo de sentido comum, que envolvem a construção de uma identificação coletiva em torno do ser mulher e das diferenças/desigualdades entre o masculino e feminino. Além disso, demarcam a percepção de si mesmas, refletindo sobre como se definiam antes e como se definem após da participação no MMC.

Considerando a necessidade de fortalecimento das causas específicas das mulheres do campo, surgem iniciativas em vários estados brasileiros, porém, mantidas com identidades próprias representadas por ações localizadas em diversas regiões do país. Podem ser citadas como exemplo de organizações locais o Movimento das Mulheres Agricultoras (MMA) em Santa Catarina, o Movimento de Mulheres Trabalhadoras Rurais (MMTR) no Rio Grande do Sul e Paraná e das extrativistas no norte e nordeste do Brasil, que apesar de nomenclaturas diferentes, representavam as mesmas lutas (BONI, 2012; PULGA, 2014; PAULILO, 2016).

Em Santa Catarina, o movimento é protagonista de mais de três décadas de história de lutas e reivindicações, resultando em conquistas importantes no campo dos direitos das mulheres camponesas (BONI, 2012; PAULILO, 2016). Boni (2012) infere que o MMA foi um dos mais atuantes movimentos de mulheres trabalhadoras rurais no Brasil no início da década de 1980. A autora, ao resgatar o histórico inicial e a trajetória do $\mathrm{MMC}$ ao longo dos anos, sistematizou seu estudo analisando o que denominou como fases do movimento, que refletem as necessidades e vivências das mulheres em cada período e contexto. 
A demarcação de fases, de acordo com Boni (2012), coincide com as décadas de 1980, 1990 e anos 2000. A primeira fase caracteriza-se pela formação inicial do movimento, a partir da identificação coletiva das mulheres em torno de questões comuns que vivenciavam em espaços domésticos (residência, unidade produtiva da família) e em espaços coletivos (comunidade, igreja, sindicato). Protagonizaram, neste período, ações reivindicativas importantes, emplacando várias bandeiras de luta essenciais para as mulheres: direito à sindicalização, aposentadoria integral, documentação que reconhecesse a profissão de agricultora e participação política das mulheres (BONI, 2012; CINELLI, 2013; PAULILO, 2016). Todas estas bandeiras eram relacionadas a questões trabalhistas, entendendo que as necessidades do movimento naquele momento, estiveram pautadas principalmente no reconhecimento da mulher como trabalhadora, vinculada a perspectiva da luta de classes.

Na segunda fase descrita por Boni (2012), questões de gênero ganham espaço e a partir dos anos de 1990, com influência do discurso feminista, as mulheres passam a refletir e focar em questões relacionadas à saúde, sexualidade e reprodução. Ocorre, por conta da opção por uma ideologia feminista, certo afastamento da Igreja Católica, que, apesar de "[...] pregar a igualdade entre homens e mulheres, tentou manter as mulheres afastadas das ideias feministas" (BONI, 2012, p. 14).

Oqueseobservanestadécada, porcontadeste redirecionamento de ideais, é a conquista do salário maternidade e da luta pela educação, entendendo que o acesso e direito à educação contribui para a emancipação da mulher. A formação da consciência das mulheres em relação às questões de gênero e da visibilidade da mulher, bem como em relação ao modelo de produção ao qual o movimento é contrário, foi ao longo do tempo acompanhando o grupo, até evidenciar a necessidade de articulação com as mulheres envolvidas em outros movimentos sociais do campo. Esta aproximação com outros movimentos possibilitou a criação, em 1995, da Articulação Nacional de Mulheres Trabalhadoras Rurais (ANMTR) e, por sua vez, contribuiu mais tarde para a formação do MMC (CINELLI, 2013).
Ao refletir sobre a terceira fase apontada por Boni (2012), retrata-se o atual momento do MMC, em que o discurso está voltado à defesa de um projeto de soberania e segurança alimentar, abrangendo todas as demais questões já defendidas pelo MMC (relacionadas a aspectos trabalhistas, gênero e saúde). Entendem que a soberania alimentar dos povos não será alcançada pelo modelo de agricultura extensivo com produção em larga escala, mas sim, por meio da agricultura camponesa e agroecológica com produção diversificada, saudável, livre de agrotóxicos e com respeito ao meio ambiente.

O MMC foi criado oficialmente em 2004, a partir da união dos vários movimentos de mulheres camponesas existentes no Brasil desde a década de 1980, marcando o momento a partir do qual se assume enquanto um movimento feminista. Integrados à Via Campesina ${ }^{4}$, unificam-se bandeiras e assumem-se novas práticas, ressignificando as antigas denominações de agricultoras e trabalhadoras rurais.

Boni (2012) destaca que a identidade camponesa é caracterizada pelo modo de viver, de se relacionar com outros grupos sociais, com o ambiente e do uso que se faz dele. Os hábitos alimentares, as comidas típicas, a música, a dança, a mística e a religiosidade são expressões do ser camponês/camponesa. A terra é considerada o lugar de reproduzir e cuidar da vida. Desta forma, as mulheres refletem sobre a diferença de ser camponesa e ser agricultora, conforme fica evidente na fala da entrevistada:

Por que, para você ser agricultora, você tem que estar na roça e plantar, colher e tal. Agora, para ser camponesa, você tem que pensar no que você faz: para que você vai plantar? Como você vai plantar? Tem que refletir sobre isso. [...] Você precisa ter também o entendimento de como a natureza age, quais são os processos dela, do cuidado com o solo, entender essas questões de como chegar lá na tua horta e olhar as plantas que nasceram espontaneamente, o que elas estão te dizendo em relação ao solo. [...] para ser camponesa, você tem que ter um pouco de noção disso. Saber, bom, se nasceu uma graminha o que a terra está 
dizendo, do enfraquecimento dela, e de como você vai recuperar isso e quais as alternativas que você tem dentro da tua unidade de produção, como é que você vai repor isso (N. M. K, dirigente estadual do MMC).

Observa-se nesta fala, uma relação de respeito com a terra, com o ambiente, característica que compõe a identidade coletiva do MMC e que após alguns anos de debates e negociações, foi consensuada e traduzida na alteração do nome do movimento. A opção pela categoria "camponês", no entendimento do MMC, está relacionada com a unidade produtiva camponesa centrada no núcleo familiar, que se dedica a uma produção agrícola de subsistência da família e comercializa parte da sua produção para garantir recursos necessários à compra de produtos que não foi possível cultivar em sua unidade produtiva (BONI, 2012).

Nesse processo dinâmico de identificação coletiva, o MMC formulou uma missão a partir da qual as ações do movimento são pautadas:

Nossa missão é a libertação das
mulheres trabalhadoras de qualquer
tipo de opressão e discriminação. Isso
se concretiza nas lutas, na organização,
na formação e na implementação de
experiências de resistência popular,
onde as mulheres sejam protagonistas
de sua história. Lutamos por uma
sociedade baseada em novas relações
sociais entre os seres humanos e deles
com a natureza ${ }^{5}$.

A importância da missão construída coletivamente pode ser verificada nas publicações do movimento em diferentes áreas de atuação. Cartilhas produzidas para orientar cursos e oficinas, folders explicativos, além de edições do Informativo MMC (jornal de circulação interna), dedicamse em algum momento a apresentação da missão, de forma a manter visibilizada a direção que o movimento segue.

Vislumbra-se, então, um movimento formado por mulheres camponesas, que vivem na/ da terra, que produzem e incentivam a produção de alimentos saudáveis, que buscam politizar temas vivenciados no cotidiano e intentam, acima de tudo, fortalecer as mulheres para que se livrem das amarras de uma sociedade ainda machista e patriarcal. Desde o princípio, desenvolvem iniciativas de fortalecer processos de emancipação e luta pelos direitos das mulheres e, a partir da segunda, com maior ênfase na terceira fase descrita por Boni (2012), as camponesas se definem enquanto movimento autônomo, feminista, classista e popular, caracterizando as diferentes dimensões da sua identidade.

Entendem que a proposta do feminismo, “[...] além de ser uma atitude política que analisa as relações de gênero, étnico-raciais e de classe, realiza o enfrentamento do patriarcado e busca a construção de uma sociedade igualitária com a socialização do poder, das riquezas e do saber" (AMTR-SUL, 2008, p. 15). Da mesma forma, não vislumbram a proposta do feminismo desarticulada do projeto de agricultura camponesa e agroecológica, inferindo que essas duas bandeiras defendidas no movimento caminham lado a lado. Para corroborar com esta perspectiva, retomam-se dois dos gritos de ordem observados na fase da pesquisa de campo: "Sem feminismo, não há agroecologia" e "Sem agroecologia, não há feminismo" ${ }^{6}$.

\section{Projeto de Agricultura Camponesa e Agroecológica: saúde e ambiente no MMC}

O desenvolvimento da agricultura "[...] pode ser compreendido como um dos principais acontecimentos da história da humanidade. O desenvolvimento de diferentes técnicas e manejos permitiu o estabelecimento gradativo da vida em comunidade" (MOHR; MOHR, 2017, p. 150). Diferentes formas e modos de produção foram assumidos ao longo do tempo, acompanhando o modelo político, econômico e social de cada época. Apesar de a literatura apontar para a existência de modelos preponderantes em cada período, Mohr e Mohr (2017) sinalizam o fato de que concomitante aos modelos hegemônicos, sempre existiram formas alternativas de agricultura.

Como baliza para a discussão pretendida, bem como para a compreensão do modelo ao 
qual o MMC se contrapõe, olhamos para o desenvolvimento da agricultura na perspectiva capitalista, o qual traz profundas transformações sociais a partir da Revolução Industrial no final do século XVIII. Avritzer (2012) aponta que, na realidade brasileira, um país que outrora fora essencialmente rural para uma rápida urbanização em curto intervalo de tempo, essas transformações são aspectos essenciais para entender a organização da sociedade civil e, nesse caso, a emergência dos movimentos sociais do campo com seus projetos e ações contrários ao modelo capitalista de produção.

$\mathrm{Na}$ Região Oeste de Santa Catarina, a realidade vivenciada pelos agricultores e agricultoras impulsionou a saída massiva do campo em direção aos centros urbanos. Renk, Dorigon e Bagnara (2014) abordam as profundas alterações nos processos produtivos e modos de vida baseados no campesinato tradicional, às quais os agricultores foram submetidos a partir do processo de modernização agrícola e instalação das agroindústrias nesta região. A época ficou marcada pela precariedade de vida e trabalho que os agricultores vivenciaram a partir do processo conhecido como Revolução Verde (RENK, 2000).

A Revolução Verde pode ser definida como a introdução em larga escala de variedades modernas de alta produtividade, objetivando intensificar a oferta de alimentos com base em uma lógica de controle da natureza. Trouxe consigo um pacote tecnológico composto por insumos químicos, sementes de laboratório, irrigação, mecanização, grandes extensões de terra e uma perspectiva ideológica de valorização do progresso (PEREIRA, 2012).

A partir deste processo "[...] a condição essencial para permanência no campo estava associada às possibilidades em acessar as políticas de subsídio do Estado para tecnificar a produção a fim de maximizá-la" (LEWER, 2017, p. 182). Porém, Lewer (2017) aponta dois grandes problemas que decorrem desta condição: primeiro, que muitos agricultores não conseguiram acessar as linhas de crédito, ficando excluídos do processo de modernização, e consequentemente não acompanhando a lógica de maximização da produção. E, segundo, aqueles que conseguiram acessar as políticas de crédito se endividaram, não conseguindo subsistir.

Esta realidade fomentou, conforme sinalizado anteriormente, a emergência de diferentes movimentos sociais no campo. Além disso, este cenário de exclusão, opressão e desigualdade contribuiu para marcar a divergência de princípios e valores entre o modelo que se implantava e que continuou evoluindo até os dias atuais, com os projetos e defesas dos movimentos sociais do campo. Evidenciam-se, de acordo com Folgado (2015, p. 188), dois grandes modelos:

O primeiro (agronegócio) traz consigo um conjunto de mazelas que afetam duramente as populações do Campo, da Floresta e das Águas, constituindose, portanto, num modelo de morte, enquanto que o segundo (agroecologia) traz consigo a perspectiva de convivência entre a produção de alimentos e as demais formas de vida existentes no espaço produtivo, constituindo-se num modelo de vida.

Para o MMC, defender um projeto de agricultura camponesa e agroecológica é propor uma lógica de desenvolvimento que considera as distintas dimensões da vida em sociedade, sejam elas econômicas, culturais, sociais ou ambientais, compreendendo-as como determinantes nos processos de saúde e doença da população, tanto do campo quanto das cidades. A concepção de saúde no MMC converge com um conceito ampliado garantido na Constituição Federal de 1988, fruto da ação coletiva de diferentes atores sociais, impulsionados inicialmente pelo Movimento pela Reforma Sanitária.

Neste sentido, também o modo de produzir baseado nos princípios da agroecologia refletem a forma como as mulheres camponesas se relacionam com o meio ambiente, com os outros seres humanos e suas imbricações com a saúde, conforme se evidencia na fala de uma participante do grupo focal:

[...] no momento que você está produzindo, que você vai produzir o alimento, você já está com os pés na terra. Estar mexendo com a terra já 
é saúde, quando você está colhendo já tem a motivação da colheita e, na hora de estar se alimentando, já é um alimento saudável, sem veneno, sem agrotóxico. Então tem tudo a ver. $\mathrm{O}$ alimento saudável que a gente produz agroecológico, ele é saúde. A alimentação com a saúde tem tudo a ver. (D. N. T., integrante do MMC município de Irani, dirigente da regional de Concórdia)

O debate promovido nas campanhas e nos cursos de formação do MMC é evidenciado em falas como esta. Trata-se de uma pauta importante nos movimentos autônomos de mulheres no final da década de 1990 e início de 2000, relembrando as fases do movimento descritas por Boni, (2012). É importante destacar que o MMC sempre faz o debate relacionado à vida, à alimentação e à saúde de forma articulada com a forma de produzir e se relacionar com o ambiente.

A compreensão do MMC acerca da necessidade de um novo projeto de agricultura, que seria uma forma de assegurar uma alimentação saudável pautada na defesa da soberania com base na preservação das próprias sementes crioulas, 'patrimônio dos povos a serviço da humanidade' materializa-se com o projeto de agricultura camponesa que, para o MMC está baseado nos princípios da agroecologia, com o cuidado do ambiente e a saúde de todos os seres vivos. (CINELLI; KREFTA, 2015, p. 206).

Estes princípios reafirmam-se nos discursos e práticas das mulheres que integram o movimento, como por exemplo, no caso de I.M, liderança do MMC no município de Palma Sola, Regional de São José do Cedro:

[...] eu mudei muito na minha casa, na minha unidade produtiva. $\mathrm{Na}$ minha horta, por exemplo, faz 20 anos que não entra veneno. Mais de 20 anos. Desde que eu entrei para o movimento, comecei a participar, eu nunca mais passei veneno de tipo nenhum e nunca mais coloquei químico nenhum na minha horta. Tudo que eu planto é organicamente e assim seria o jeito certo de a gente fazer. Comer comida saudável para não ficar doente.

Anteriormente abordou-se a questão da identificação coletiva das mulheres e a transformação particular que as participantes percebem em si mesmas. Da mesma forma, ao analisar suas falas, percebemos que o pertencimento a este grupo social conduz a uma mudança nas práticas cotidianas que, por sua vez, traduzem-se em mudanças nas relações familiares, entre mulheres, homens, filhos e filhas, e desses com o ambiente que os cerca. Conforme Cinelli e Krefta (2015, p. 209) "a construção de novas relações se efetivam a partir de novas práticas que, no Movimento de Mulheres Camponesas, estão ligadas à produção de alimentos saudáveis”.

As camponesas compreendem que construir esse modo de vida é um processo lento e gradual, pois as mudanças desejadas, diante de uma sociedade que ainda cultiva um modelo patriarcal e machista, devem ser constituídas nas relações cotidianas, produzindo transformações nas famílias, depois na comunidade, município, região etc. Ao discutir novas formas de relações, muitos temas foram se estreitando e se constituindo como destaques para o MMC, como a questão da recuperação, produção e melhoramento das sementes crioulas de hortaliças, a soberania e segurança alimentar, a produção de alimentos saudáveis, o cultivo e consumo de plantas medicinais e os cuidados alternativos em saúde (CINELLI, 2013; CINELLI, KREFTA, 2015).

Percebe-se a ênfase na noção de cuidado quanto à abordagem do tema saúde. $\mathrm{O}$ cuidar adotado pelo MMC extrapola a ideia de saúde/ doença, sendo que suas bandeiras de luta neste campo convergem com a construção do projeto de agricultura camponesa e agroecológica como contraponto ao modelo vigente (AMTR-SUL, 2008). O cuidado é entendido como princípio norteador da vida e das relações nela estabelecidas.

Juntamente com a perspectiva de cuidar da vida, há uma valorização e respeito aos saberes das camponesas. As mulheres têm cuidado de si mesmas e de suas famílias utilizando plantas medicinais, a partir de um conhecimento acumulado ao longo da história da humanidade e na história de sua própria família e/ou comunidade. A partir do 
MMC as mulheres têm retomado, reconstruído e ressignificado esses saberes, de forma coletiva. Verifica-se no diálogo a seguir a importância atribuída a este jeito de cuidar proveniente do saber popular:

P4: [...] Temos que valorizar o que a gente sabe. E se a gente se valoriza, os outros também vão valorizar a gente. Que nem dos benzimentos, que a gente ainda se apega muito nos benzimentos que as nossas mães e as nossas avós faziam e que dava muito certo (I. M., liderança do MMC município de Palma Sola, regional de São José do Cedro).

P1: Ah! Isso é verdade. Nós se curava só com o poder dos benzimentos e agora tem que tomar um monte de remédios. (G. M., liderança do MMC município de Planalto Alegre, regional de Chapecó).

P5: É, não podemos perder isso. Nós aqui, das mulheres camponesas, a gente diz que nós somos todas um pouco bruxas. E é verdade, porque a gente encontra na natureza tudo que é remédio. A gente usa as plantas para fazer nossas poções mágicas. (D. N. T., integrante do MMC município de Irani, dirigente da regional de Concórdia).

Há, de certa forma, um pesar na fala das participantes ao referenciar que o conhecimento acumulado ao longo do tempo e da história das famílias possa estar se perdendo ao ponto de desaparecer em pouco tempo. Por este motivo, a relevância em garantir que estes conhecimentos também estejam contemplados no projeto defendido pelo movimento, suscitando formações, oficinas, projetos horto medicinais e troca de experiências entre as mulheres e seus saberes acumulados.

Para dar suporte e fortalecer uma ideia comum sobre o projeto de agricultura camponesa e agroecológica, o MMC realiza formações/estudos, tanto individualmente quanto a partir de parcerias estabelecidas com outras entidades e organizações, como universidades, órgãos governamentais, movimentos do campo e urbanos etc. Os cursos e capacitações subsidiam os conhecimentos necessários para o desenvolvimento de práticas agroecológicas, incentivando as mulheres a estudar o solo, sua composição, o que as plantas que nascem naquele espaço indicam sobre o tipo de solo, se está faltando ou sobrando algo, dentre outros aspectos. A metodologia das formações é sempre participativa, construída juntamente com as camponesas na perspectiva da educação popular.

A partir da leitura e análise dos documentos produzidos pelo movimento, da participação em ações em que o MMC esteve presente e da interlocução com as camponesas que compuseram a amostra desta pesquisa, é possível inferir que $\mathrm{O}$ MMC atribui importância fundamental às formações e estudos ofertados às mulheres. A partir deles, as camponesas se instrumentalizam, constroem coletivamente novos saberes e práticas e disseminam os conhecimentos construídos incutindo mudanças significativas em seu entorno:

[...] Então, uma das conscientizações que a gente faz [nos cursos e formações] é sobre a alimentação saudável, que tem tudo a ver com saúde. [...] A gente aprende que mulher tem direito à saúde, que mulher tem direito à vida, que tem direito a alimentação saudável. E a gente sai de lá com a certeza que mulher é ser humano também, e que tem que ser tratada como gente. E que a mulher, ela começa lá na casa dela a fazer a mudança, a mudança que começa primeiro em si mesma e depois de levar para as outras pessoas (D. N. T., integrante do MMC município de Irani, dirigente da regional de Concórdia).

As definições utilizadas pelas mulheres na produção dos documentos e materiais disponibilizados para estudo correspondem à sistematização de vários anos de trabalho de mulheres vinculadas ao MMC, e refletem as articulações entre os conceitos de saúde e ambiente como temáticas transversais dentro das discussões e ações do movimento. Os materiais são relacionados principalmente às práticas saudáveis que envolvem a preservação da natureza, cuidado e zelo com a terra, cuidado de si, do próprio corpo, a necessidade de transformação das relações entre mulheres e homens e destes com a natureza, a valorização de si e dos conhecimentos acumulados ao longo do 
tempo, do cultivo e consumo de plantas e ervas medicinais, dentre outros.

Estes materiais são ferramentas pedagógicas utilizadas nos cursos e capacitações que contribuem para a formação de consensos (MELUCCI, 2001) sobre as bandeiras de luta defendidas pelo movimento. São produções e construções coletivas das mulheres que levam em consideração suas vivências e experiências no desenvolvimento de práticas agroecológicas.

Por intermédio de oficinas e cursos, utilizando os materiais como guia de estudo, as mulheres se apropriam do conhecimento difundido pelo movimento; fortalecem as práticas relacionadas a agricultura camponesa e agroecológica; aprendem e potencializam práticas alternativas de saúde com plantas e ervas medicinais, resgatando saberes e conhecimento popular em saúde que estão de acordo com o modelo de agricultura que defendem; participam e se reconhecem como pertencentes ao movimento e vivenciam relações diferenciadas com o ambiente que habitam.

\section{Considerações}

Ao olhar para as descrições e reflexões aqui suscitadas, compreende-se que ao defender um modelo de agricultura agroecológica, camponesa (e de base feminista), o movimento não debate de forma desarticulada os temas propostos para análise neste artigo. Na realidade, compreende-se que não há como dissociar um conceito de outro. Visualiza a saúde como a inter-relação entre ambiente/ sociedade/corpo e relações.

Na contramão de uma perspectiva capitalista de agricultura, que visa à maximização da produção para atender as exigências do mercado, o MMC vem, juntamente com outros movimentos sociais do campo, resistindo e combatendo o modelo ao qual se contrapõem desde sua origem. Construiu ao longo dos anos uma história de lutas e conquistas importantes não apenas para as mulheres do campo, como também para as famílias camponesas e urbanas. Protagonistas de uma forma peculiar de compreensão e intervenção sobre a realidade cotidiana, o movimento defende um projeto de agricultura camponesa de base agroecológica que implica não apenas em mudanças na forma de produzir, mas em transformações significativas no âmbito das relações em diferentes dimensões da experiência humana.

Compreendem este projeto não apenas como um modelo para a agricultura, mas o incorporam como um modo de vida que enseja novas relações entre mulheres, homens e ambiente. Relações baseadas em respeito mútuo, sem opressão ou subordinação, sem uso irresponsável dos recursos ambientais, como a utilização exacerbada de agrotóxicos e sementes geneticamente modificadas que trazem riscos à saúde humana. Relações baseadas no cuidado de si e dos outros, com projetos, campanhas e ações focadas na produção de alimentos saudáveis, agroecológicos, recuperação de sementes crioulas de hortaliças, valorização do saber popular acumulado ao longo da história da humanidade em relação ao plantio e uso de ervas medicinais, bem como reconhecimento da importância das benzedeiras e rezadeiras para a população do campo.

\section{Notas}

1 Consulta em materiais e documentos produzidos no/pelo movimento (publicados entre 2008 e 2015): Revista Camponesa; Cartilha Mulheres camponesas produzindo alimentos saudáveis; Folder Economia feminista a partir da campanha nacional de produção de alimentos saudáveis; Cartilha Produção de plantas medicinais aromáticas; Cartilha Horto medicinal, legislação dos fitoterápicos e comercialização; Folder Mulheres camponesas em defesa da saúde pública; Cartilha Mulheres Camponesas construindo autonomia através da produção de alimentos saudáveis (1 e 2); Cartilha Mulheres Camponesas em defesa da saúde e da vida; Folder Diversificando o conhecimento para a saúde humana e vegetal.

2 Destaque para participação em duas etapas do curso "Organização Produtiva de Mulheres e promoção da autonomia por meio do estímulo à prática agroecológica" (2015 e 2016) e do I Encontro Nacional de Saúde das Populações do Campo, da Floresta e das Águas: cuidar, promover, preservar - saúde se conquista com luta popular, realizado em Brasília, 2015. Outros espaços de observação: oficinas, manifestações, reuniões de planejamento, visita a hortos-medicinais cultivados por militantes do MMC. 
3 Em Santa Catarina, no período da pesquisa de campo (entre 2015 e 2016), o MMC/SC se organizava em 16 regionais, a saber: Caçador, Concórdia, Chapecó, Campo Erê, Descanso, Joaçaba, Lages, Mafra, Maravilha, Quilombo, Rio do Campo, São José do Cedro, São Miguel do Oeste, Sul e Xanxerê. A partir da Assembleia Estadual realizada em outubro de 2017, as regionais foram revistas e a partir de 2018, nova configuração poderá ser observada na estrutura organizativa do movimento.

4 "La Vía Campesina es el movimiento internacional que agrupa a millones de campesinos y campesinas, pequeños $y$ medianos productores, pueblos sin tierra, indígenas, migrantes y trabajadores agrícolas de todo el mundo. Defiende la agricultura sostenible a pequeña escala como un modo de promover la justicia social y la dignidad. Se opone firmemente a los agronegocios y las multinacionales que están destruyendo los pueblos y la naturaliza" (LA VIA CAMPESINA, 2011, s/p. Disponível em: <http:// viacampesina.org/es/index.php/organizaciainmenu-44/ iquisomos-mainmenu-45)>. Acesso em: Abr. 2016.

5 Dados disponíveis em: <http://www.mmcbrasil.com. br/site/node/45>

6 Os gritos de ordem referenciados no texto provêm de anotações em diário de campo.

\section{Referências}

ARTICULAÇÃO DE MULHERES TRABALHADORAS RURAIS - AMTR-SUL. Mulheres camponesas em defesa da saúde e da vida. Passo Fundo/RS: Passografic, 2008.

AVRITZER, Leonardo. Sociedade civil e Estado no Brasil: da autonomia à interdependência política. Opinião Pública, Campinas. v. 18, n. 2, p. 383-398, nov. 2012. Disponível em: <http://www.scielo.br/pdf/ op/v18n2/a06v18n2.pdf>. Acesso em: jun. 2016.

BONI, Valdete. De agricultoras a camponesas: o movimento de mulheres camponesas de Santa Catarina e suas práticas. Tese (Doutorado) - Universidade Federal de Santa Catarina, Florianópolis/SC, 2012.

CINELLI, Catiane. Movimento de Mulheres Camponeses: 30 Anos. Grifos, Chapecó (SC), v. 22, n.34/35, p. 38-49. 2013. ISSN 2175-0157.

; KREFTA, Noemi M. Saúde e ambiente: a experiência no Movimento de Mulheres Camponesas. In: BRASIL, Ministério da Saúde.
Saúde e ambiente para as populações do campo, da floresta e das águas. Brasília: Ministério da Saúde, 2015.

FOLGADO, Cleber. Impactos dos modelos de desenvolvimento para as populações do campo, da floresta e das águas. In: BRASIL, Ministério da Saúde. Saúde e ambiente para as populações do campo, da floresta e das águas. Brasília: Ministério da Saúde, 2015.

GOHN, Maria da Glória. Teorias dos movimentos sociais: paradigmas clássicos e contemporâneos. São Paulo: Loyola, 2006.

GOSS, Karine Pereira; PRUDENCIO, Kelly. O conceito de movimentos sociais revisitado. In: Em Tese, Florianópolis, v. 1, n. 2, p. 75-91, jan. 2004. ISSN 1806-5023.

LEWER, Rafael F. Campesinato e seu retorno ao debate político a partir do movimento dos pequenos agricultores. In: BONI, Valdete (Org.). Mulheres camponesas e agroecologia. Curitiba/PR: CRV, 2017.

MELUCCI, Alberto. A invenção do presente: movimentos sociais nas sociedades complexas. Petrópolis/RJ: Editora Vozes, 2001.

MOHR, Matheus F.; MOHR, Naira E. R. A insustentabilidade da agricultura no atual modelo de produção. In: BONI, Valdete (Org.). Mulheres camponesas e agroecologia. Curitiba/PR: CRV, 2017.

PAULILO, Maria Ignez. Mulheres rurais: quatro décadas de diálogo. Florianópolis/SC: Ed. da UFSC, 2016.

PEREIRA, Mônica C. B. Revolução verde. In: CALDART, R. S. et al. (Orgs.). Dicionário da Educação do campo. Rio de Janeiro: Escola Politécnica de Saúde Joaquim Venâncio, Expressão Popular, 2012.

POLI, Odilon. Leituras em movimentos sociais. Chapecó: Grifos, 2008.

PULGA, Vanderleia L. Mulheres camponesas plantando saúde, semeando sonhos, tecendo 
redes de cuidado e de educação em defesa da vida. Tese (Doutorado) - Universidade Federal do Rio Grande do Sul, Porto Alegre, 2014.

RENK, A; DORIGON, C; BAGNARA, M. Juventude rural e mudança social. In: RENK, Arlene; DORIGON, Clóvis (Orgs.). Juventude rural, cultura e mudança social. Chapecó/SC: Argos, 2014.
RENK, Arlene. Sociodicéia às avessas. Chapecó/ SC: Grifos, 2000.

SCHERER-WARREN, Ilse. Das mobilizações às redes de movimentos sociais. Rev. Sociedade e Estado, v. 21, n. 1, p.109-130, 2006. ISSN 0102-6992. 